\title{
What makes community psychiatric nurses label non-psychotic chronic patients as 'difficult': patient, professional, treatment and social variables
}

\author{
B. Koekkoek • B. van Meijel • B. Tiemens • \\ A. Schene $\cdot$ G. Hutschemaekers
}

Received: 17 March 2010/Accepted: 23 June 2010/Published online: 3 July 2010

(C) The Author(s) 2010. This article is published with open access at Springerlink.com

\begin{abstract}
Purpose To determine which patient, professional, treatment and/or social variables make community psychiatric nurses (CPNs) label non-psychotic chronic patients as 'difficult'.

Methods A questionnaire was designed and administered to 1,946 CPNs in the Netherlands. Logistic regression was used to design models that most accurately described the variables that contributed to perceived difficulty.

Results Six variables were retained in the final logistic model. Perception-related variables (feeling powerless, feeling that the patient is able but unwilling to change, and pessimism about the patient's change potential) dominated treatment-related variables (number of contacts per week and admission to a locked ward in the last year) and social variables (number of psychosocial problems).
\end{abstract}

B. Koekkoek $(\bowtie)$

Department of Outpatient Community Care,

Altrecht Mental Health Care, Oude Arnhemseweg 260, 3705 BK Zeist, The Netherlands

e-mail: b.koekkoek@altrecht.nl

B. Koekkoek · B. Tiemens - G. Hutschemaekers

Institute for Professionalization, Gelderse Roos Mental Health Care, Wolfheze, The Netherlands

B. van Meijel

Research Group Mental Health Nursing, INHolland University for Applied Sciences, Amsterdam, The Netherlands

\footnotetext{
A. Schene

Department of Psychiatry, Academic Medical Centre, University of Amsterdam, Amsterdam, The Netherlands

G. Hutschemaekers

Academic Centre of Social Sciences, Radboud University,

Nijmegen, The Netherlands
}

Conclusion This research shows that perceived difficulty is related to complex treatment situations, not so much to individual patient characteristics. If the constructed model has good predictive qualities, which remains to be tested in longitudinal research, it may be possible to accurately predict perceived patient difficulty. When used as a screening tool, such a model could improve treatment outcomes.

Keywords Public mental health - Social psychiatry · Substance abuse disorders - Affective disorders . Personality disorders · Psychiatric nursing

\section{Introduction}

Health care professionals do perceive certain patients as 'difficult', both in physical [1-5] and mental health care $[6,7]$. In general medicine, perceived difficulty has found to be associated with multiple somatic complaints and psychiatric disorders [2-5]. In psychiatry, patients with severe mental illness in general are often considered difficult to treat [8], but few empirical studies have been undertaken to clarify the underlying reasons for this perceived difficulty [7]. Small studies of earlier date show that patients with psychotic or personality disorders are most likely to be perceived as difficult, with patients with mood disorders ranking next. 'Difficult' psychotic patients are characterized by professionals as 'withdrawn' and 'hard-to-reach', 'difficult' patients with personality disorders as 'demanding' and 'claiming', and 'difficult' patients with mood disorders as 'dependent' and 'demoralizing' [7].

The label 'difficult' is pejorative, stigmatizing, and imprecise [9] but often used in everyday mental health care, especially in services that are not highly selective such as public and community mental health centers [10]. From 
earlier work, we can distinguish three different meanings of the term. The first meaning refers to patients that do not improve or relapse repeatedly, so-called 'difficult-to-treat' patients $[7,11,12]$. The second refers to patients that are interpersonally challenging, so-called 'difficult' patients that supposedly have a complex character or personality [7, 13]. The third meaning refers to patients who find themselves in complex social and treatment situations, patients that have numerous social problems, frequently use inpatient and outpatient emergency services, and have difficulties in finding the right helping agency to have their needs met [14, 15]. The label 'difficult' thus represents a complex interplay of several factors and may refer to patient characteristics in terms of illness, behavior or character. It may, however, also reflect professionals' lack of skills and motivation, or environmental factors such as patients' social system or clinicians' professional system [15].

In general, the 'difficult'-label is associated with a low quality of the therapeutic alliance between patient and professional, which in itself is a predictor of a more negative treatment outcome [16, 17]. Also, 'difficult' patients more often lack a treatment plan, a key clinician and continuity of care in general, than other patients [10]. Service use of these patients is high and thus costly [1820]. Therefore, it is relevant to understand which variables account for the perception of patients as difficult by professionals. Timely recognition of these variables may prevent perceived difficulty and thus result in improved treatment outcome. Currently, however, many of these factors are theorized or hypothesized only, and not empirically assessed in a larger study.

In this study, we focused on patients with severe nonpsychotic mental illness. The percentages of non-psychotic patients in long-term community mental health services are estimated between 20 and 50\% [21-25]. The key clinicians in long-term care for these patients often are community psychiatric nurses (CPNs), the most numerous professionals in community mental health in several countries [23, 26-28]. In this paper, we report on the perception of CPNs in community mental health care for non-psychotic chronic patients. The aim of this study is to determine which patient, professional, treatment and/or social variables make CPNs label non-psychotic chronic patients as 'difficult', in order to define this term more accurately, and eventually improve care for patients labeled as such.

\section{Methods}

Design and participants

A cross-sectional survey design was used to describe community psychiatric nursing care for non-psychotic chronic patients, assessing several patient, professional, treatment and social variables. The sampling frame was the database of the Dutch Association for Community Psychiatric Nurses (DACPN). This database includes $1,946 \mathrm{CPNs}$, about $70 \%$ of the total estimated number of 2,900 Dutch CPNs. An electronic questionnaire was developed and was available online between mid-December 2007 and late January 2008. CPNs were invited to participate by a postal letter in which the study was introduced as a general survey into current $\mathrm{CPN}$ practice. Two weeks and 4 weeks after this letter, nonresponders received a reminder in the form of a postal card.

\section{Measures}

The questionnaire was constructed by the authors, based on previous research among CPNs and previous Delphiresearch on problems in the care of difficult patients among community mental health experts [15]. It consisted of 19 questions related to the CPN and the service he or she worked in. Another 23 items (rateable on a 7 point Likertscale) were about the perceptions of the care for a selected patient. Furthermore, it included 23 questions about clinical, treatment and social characteristics of the selected patient in care. The first paper version of the questionnaire was tested by $27 \mathrm{CPNs}$ after which some questions were omitted and text phrasing was altered. A second, internetbased version was tested by another six CPNs after which technical software-related errors were corrected.

Before answering the questionnaire, CPNs were asked to select a patient meeting the criteria for non-psychotic severe and persistent mental disorder [29]: a non-psychotic diagnosis (excluding schizophrenia, bipolar disorder and organic disorder), two or more years in psychiatric care and a GAF-score at or below 50. To ensure random sampling of patients, a fixed procedure was used. CPNs should select the first eligible patient on their next working day from their agenda (or progress as far ahead in time as necessary to encounter a patient meeting the criteria).

Degree of perceived difficulty, the dependent variable in this study, was measured by the question 'to which extent do you rate this patient as "difficult"?', scored on the same 7-point Likert-scale as the other perception-related items. At the time of the study, we were unaware of validated measures of psychiatric patients' difficulty. Furthermore, single-item questions such as ours have been used widely before $[2,5,10,30]$.

\section{Analysis}

Due to a bimodal distribution (Table 1), the dependent variable was dichotomized into two values: no perceived difficulty (score 1-4) and perceived difficulty (5-7). Logistic regression was used to determine the effects of the 
Table 1 Distribution of perceived difficulty over selected patients on 7 point Likert-scale

\begin{tabular}{lc}
\hline $\begin{array}{l}\text { Likert-score }(\text { perceived difficulty } \\
1=\text { low, } 7=\text { high })\end{array}$ & $\begin{array}{l}\text { Number of selected } \\
\text { patients }(\%)\end{array}$ \\
\hline 1 & $10(2.1)$ \\
2 & $74(15.8)$ \\
3 & $165(35.2)$ \\
4 & $83(17.7)$ \\
5 & $100(21.3)$ \\
6 & $29(6.2)$ \\
7 & $4(9)$ \\
& $465(99.1)^{\mathrm{a}}$ \\
\hline
\end{tabular}

${ }^{\mathrm{a}}$ Of the 469 patients described by CPNs, data of 4 patients on perceived difficulty was missing

patient, professional, treatment and social variables on perceived difficulty. Linearity of the relation between each variable and the dependent variable was assessed using cross tables for dichotomous and categorical variables, and scatter plots for continuous variables. Since some variables did not have a linear association with the dependent variable, these were categorized using dummy variables. Non-linearity was also found in 7 of the 23 continuous variables related to the professional's perception that were measured on the Likertscale. These seven variables were omitted since categorization of the Likert-scale was not considered a valid way to interpret this non-linearity. Bivariate analyses were used to reduce the number of variables, since this was too high after categorisation for the number of cases to produce a stable model. A significance value of $p \leq 0.20$ was used to select variables to be included in the further analysis.

Two models were made, one for the continuous perception-related variables and one for the (predominantly) dichotomous and categorical other variables. A third and final model was constructed by combining all variables retained in the previous models. In the first two models, variables stayed in the model at $p \leq 0.10$ to prevent preliminary exclusion of relevant factors. In the final model, variables remained in the model at $p \leq 0.05$. For all models, backward procedures were followed. Interaction effects of the variables included in the final models were explored $(p \leq 0.10)$, which was also done for collinearity [31]. Goodness-of-fit was established using the classification table, and the Hosmer and Lemeshow test to test the models' accuracy of predicting perceived difficulty [32]. All analyses were performed with SPSS version 15.

\section{Results}

The 1,946 CPNs answered 776 questionnaires (response rate: $40 \%$ ). Of these participants, about $20 \%$ did not carry their own case-load of patients between 18 and 60 years of age. Another $20 \%$ did not have non-psychotic chronic patients under their care, resulting in 469 CPNs describing a patient (Table 2). Most CPNs were between 40 and 50 years of age. They predominantly worked in long-term care departments ( $\geq 2$ years) of mental health institutes. They had a mean case-load size of 52.2 (sd 31.7, median 50) of which 12.4 (sd 13.6, median 8) were non-psychotic chronic patients ( $23.8 \%$ of the total case-load).

Table 2 Characteristics of surveyed Community Psychiatric Nurses (CPNs)

\begin{tabular}{|c|c|}
\hline & $n=469(\%)$ \\
\hline \multicolumn{2}{|l|}{ Sex } \\
\hline Female & $248(52.9)$ \\
\hline \multicolumn{2}{|l|}{ Age } \\
\hline Mean (sd) & $46.9(7.3)$ \\
\hline $20-29$ & $10(2.1)$ \\
\hline $30-39$ & $53(11.3)$ \\
\hline $40-49$ & $225(48.0)$ \\
\hline $50-59$ & $175(37.3)$ \\
\hline$>60$ & $6(1.3)$ \\
\hline \multicolumn{2}{|l|}{ Education } \\
\hline CPN & $412(87.8)$ \\
\hline $\mathrm{CPN}+$ & $204(43.5)$ \\
\hline $\mathrm{CPN}+$ Master & $11(2.3)$ \\
\hline Mean years of CPN-experience (sd) [range] & $11.4(8.6)[0-35]$ \\
\hline \multicolumn{2}{|l|}{ Work setting } \\
\hline Mental health services & $411(87.6)$ \\
\hline Addiction services & $35(7.5)$ \\
\hline Private practice & $34(7.2)$ \\
\hline Forensic psychiatry & $10(0.6)$ \\
\hline General hospital or academic psychiatry & $6(1.3)$ \\
\hline Otherwise & $15(3.1)$ \\
\hline \multicolumn{2}{|l|}{ Type of care } \\
\hline Emergency services & $133(28.4)$ \\
\hline Community-based $<2$ years & $301(64.2)$ \\
\hline Community-based $\geq 2$ years & $307(65.5)$ \\
\hline Partial hospital & $17(3.6)$ \\
\hline Inpatient $<2$ years & $21(4.5)$ \\
\hline Inpatient $\geq 2$ years & $9(1.9)$ \\
\hline \multicolumn{2}{|l|}{ Evidence-based practice } \\
\hline Mean hours of supervision (sd) [range] & $1.5(1.15)[0.2-8]$ \\
\hline Method described in the work setting & $202(43.1)$ \\
\hline Method described in the literature & $110(23.5)$ \\
\hline No or non-described method & $157(33.5)$ \\
\hline \multicolumn{2}{|l|}{ Case-load size } \\
\hline Mean total number (sd) [median (range)] & $52.2(31.7)[50(1-250)]$ \\
\hline $\begin{array}{l}\text { Mean number of non-psychotic chronic } \\
\text { patients (sd) [median (range)] }\end{array}$ & $12.4(13.6)[8(1-95)]$ \\
\hline
\end{tabular}


Table 3 Characteristics of patients described by Community Psychiatric Nurses (CPNs)

\begin{tabular}{|c|c|}
\hline & $n=467(\%)^{\mathrm{a}}$ \\
\hline \multicolumn{2}{|l|}{ Sex } \\
\hline Female & $269(57.4)$ \\
\hline \multicolumn{2}{|l|}{ Age } \\
\hline $18-24$ & $43(9.2)$ \\
\hline $25-34$ & $78(16.6)$ \\
\hline $35-44$ & $143(30.5)$ \\
\hline $45-54$ & $138(29.4)$ \\
\hline $55-60$ & $65(13.9)$ \\
\hline In psychiatric care $\geq 3$ years & $349(74.5)$ \\
\hline No legal confinement & $387(82.5)$ \\
\hline \multicolumn{2}{|l|}{ Diagnosis (DSM IV) } \\
\hline \multicolumn{2}{|l|}{ Axis I } \\
\hline Mood disorder & $228(48.6)$ \\
\hline Anxiety disorder & $107(22.8)$ \\
\hline Substance abuse disorder & $102(21.7)$ \\
\hline Somatoform disorder & $8(1.7)$ \\
\hline Factitious Disorder & $1(0.2)$ \\
\hline Dissociative disorder & $30(6.4)$ \\
\hline Sexual disorder & $7(1.5)$ \\
\hline Eating disorder & $14(3.0)$ \\
\hline Impulse control disorder & $43(9.2)$ \\
\hline ADHD/autism & $48(10.2)$ \\
\hline Adjustment disorder & $61(13.0)$ \\
\hline No or deferred diagnosis & $33(7.0)$ \\
\hline Other & $23(4.9)$ \\
\hline Primary diagnosis on Axis I & $208(44.3)$ \\
\hline Mean number of Axis I diagnoses (sd) [range] & $1.5(0.81)[1-5]$ \\
\hline \multicolumn{2}{|l|}{ Axis II } \\
\hline Cluster A & $33(7.0)$ \\
\hline Cluster B & $210(44.8)$ \\
\hline Cluster C & $83(17.7)$ \\
\hline NOS & $52(11.1)$ \\
\hline No or deferred diagnosis & $89(19.0)$ \\
\hline Axis III any diagnosis & $152(32.4)$ \\
\hline Axis IV mean number of problems(sd) [range] & 3.3 (1.8) [0-9] \\
\hline \multicolumn{2}{|l|}{ Axis V GAF-score } \\
\hline $41-50$ & $337(71.9)$ \\
\hline $31-40$ & $98(20.9)$ \\
\hline $21-30$ & $18(3.8)$ \\
\hline $10-20$ & $15(3.2)$ \\
\hline Social contacts $\leq 3$ & $387(82.6)$ \\
\hline
\end{tabular}

${ }^{a}$ Due to missing data on characteristics of 2 of 469 patients described by CPNs

The selected patients (Table 3) show a high prevalence of mood disorders $(48.6 \%)$, cluster-B personality disorders (44.8\%), and a somewhat lower prevalence of anxiety
(22.8\%) and substance abuse disorders $(21.7 \%)$. Furthermore, over $32.4 \%$ of them had a diagnosis on Axis III, the mean number of psychosocial problems on Axis IV was 3.3 and most patients (71.9\%) had a GAF-score on Axis V between 41 and 50. Of all 465 described patients, 28.4\% was perceived difficult by their treating CPNs.

After bivariate screening of patient, professional, treatment and social variables $(p \leq 0.20), 39$ variables were selected to be included in two logistic regression models (Table 4). The first model contained all variables except the 16 perception-related items. Perceived difficulty showed a moderate to strong relation to the GAF-score, the number of Axis I diagnoses, the presence of an Axis IIIdiagnosis and the number of psychosocial problems on Axis IV (Table 5, model 1). Apart from these patient and social variables, the number and type (especially intensive and acute care) of psychiatric treatment used by the patient were related to the label 'difficult'. The second model (Table 5, model 2), in which the 16 items related to the professional's perception of patient and treatment were entered, yielded a compact model of five continuous variables of which 'feeling powerless' had the strongest relation to perceived difficulty. The third model (Table 5, model 3) combined the variables retained in the previous two models, resulting in a final model with six variables. Patient variables were no longer present in this model while treatment, social and perception-related variables remained. The number of psychosocial problems proved to have the strongest relation to perceived difficulty with feelings of powerlessness being almost as strongly related.

In terms of goodness-of-fit, this model classified patients correct in $74.2 \%$ of cases and the Hosmer and Lemeshow test was not significant $\left(x^{2}=11.92, d f=8, p=0.16\right)$, indicating support for our model. The previous two models classified patients correct in 70.3 and $69.9 \%$ of cases, respectively, with Hosmer and Lemeshow tests neither being significant.

\section{Discussion}

From this study, we may conclude that Community Psychiatric Nurses (CPNs) label about a third to a fourth of their total patient caseload as 'difficult'. We found that a relatively small number of (six) characteristics accounts for the perception of non-psychotic chronic patients as 'difficult'. To our knowledge, this is the first study that investigates such characterization of non-psychotic chronic patients.

Findings

The $28 \%$ of patients perceived as difficult is quite high compared to findings from other research: $6 \%$ among 
Table 4 Significance of variables in bivariate screening $(n=465)$

\begin{tabular}{|c|c|}
\hline Professional variables & $p$ \\
\hline Sex & 0.682 \\
\hline Age category & 0.055 \\
\hline Educational level & 0.194 \\
\hline Number of working hours & 0.741 \\
\hline Work setting & 0.068 \\
\hline Years of CPN-experience & 0.030 \\
\hline Type of care & 0.073 \\
\hline Evidence-based practice & 0.869 \\
\hline Hours of supervision & 0.273 \\
\hline Case-load size & 0.064 \\
\hline \multicolumn{2}{|l|}{ Perception-related items } \\
\hline 'I expect that this patient will not improve much as a result of my care' & 0.00 \\
\hline 'I feel powerless towards this patient' & 0.00 \\
\hline 'I do not experience success in the care of this patient' & 0.00 \\
\hline 'I feel pressured by this patient' & 0.00 \\
\hline 'This patient is dependent on me' & 0.00 \\
\hline 'This patient has too high expectations of his/her contact with me' & 0.00 \\
\hline 'This patient is not hopeful about the care offered' & 0.00 \\
\hline 'There is no clear view on the problems and the treatment of this patient' & 0.00 \\
\hline 'I feel that this patient is able but unwilling to change' & 0.00 \\
\hline 'This patient is not offered intensive treatment while he/she should be' & 0.00 \\
\hline 'This patient's treatment is not consistent' & 0.00 \\
\hline 'I do not have faith in the treatment of this patient' & 0.00 \\
\hline 'I am pessimistic about the patient's change capacities' & 0.00 \\
\hline 'People around this patient think that he/she is able but unwilling to change' & 0.00 \\
\hline 'This patient causes trouble within his/her family or social system' & 0.00 \\
\hline 'This patient plays hardly any role in his/her family or social system' & 0.22 \\
\hline \multicolumn{2}{|l|}{ Patient variables } \\
\hline Sex & 0.738 \\
\hline Age category & 0.045 \\
\hline Years of psychiatric care & 0.487 \\
\hline Legal confinement (once, repeatedly or constantly during last year) & 0.019 \\
\hline Axis I diagnosis & $5 \times p \leq 0.20$ \\
\hline Axis II diagnosis & 0.054 \\
\hline Number of Axis I diagnoses & 0.006 \\
\hline Primary diagnosis on Axis I or Axis II & 0.837 \\
\hline Axis III-diagnosis (no/yes) & 0.002 \\
\hline \multicolumn{2}{|l|}{ Social variables } \\
\hline Number of psychosocial problems (Axis IV) & 0.000 \\
\hline GAF-score (Axis V) & 0.000 \\
\hline Number of social contacts $(\leq 3 />3)$ & 0.045 \\
\hline \multicolumn{2}{|l|}{ Treatment variables } \\
\hline Number of mental health contacts per month $(\leq 1 />1)$ & 0.000 \\
\hline Regularity of contacts (regular, irregular) & 0.471 \\
\hline Treatment goal (recovery, prevent relapse, structure life, monitor risk behavior, unclear) & $2 \times p \leq 0.20$ \\
\hline Number of mental health professionals involved & 0.435 \\
\hline Cooperation of mental health professionals involved (none, irregular, regular) & 0.414 \\
\hline Additional psychiatric services (emergency services, admission, partial hospital) & $3 \times p \leq 0.20$ \\
\hline Number of additional psychiatric services & 0.006 \\
\hline Number of non-psychiatric institutions involved & 0.302 \\
\hline
\end{tabular}

psychiatric inpatients with both psychotic and non-psychotic disorders [30] and $15 \%$ of ambulatory patients with physical disorders $[3,4]$. It is, however, lower than the $37 \%$ of high medical service-using patients of a health maintenance organization perceived as 'frustrating' by providers [2]. Unfortunately, since these populations differ substantially 
Table 5 Multivariable logistic regression models for perceived difficulty using three sets of variables (descriptive variables, perception-related variables and combined) $(n=465)$

\begin{tabular}{|c|c|c|c|c|c|}
\hline & $\mathrm{OR}^{\mathrm{a}}$ & $95 \% \mathrm{CI}$ & $\mathrm{AOR}^{\mathrm{b}}$ & $95 \% \mathrm{CI}$ & $p$ \\
\hline \multicolumn{6}{|l|}{ Model 1: patient, professional, treatment and social variables $(p \leq 0.10)$} \\
\hline \multicolumn{6}{|l|}{ Dichotomous/categorical } \\
\hline Substance abuse disorder (no/yes) & 1.42 & $0.89-2.28$ & 0.50 & $0.27-0.94$ & 0.031 \\
\hline Diagnosis Axis III (no/yes) & 1.97 & $1.30-3.00$ & 2.02 & $1.25-3.27$ & 0.004 \\
\hline $\mathrm{CPN}$ contacts per week $(\leq 1 />1)$ & 2.65 & $1.75-4.02$ & 2.07 & $1.27-3.37$ & 0.003 \\
\hline Use of crisis intervention services during last year (no/yes) & 2.10 & $1.38-3.19$ & 1.97 & $1.05-3.68$ & 0.033 \\
\hline Use of open closed ward during last year (no/yes) & 1.84 & $1.17-2.88$ & 1.90 & $0.97-3.76$ & 0.063 \\
\hline Use of locked admission ward during last year (no/yes) & 2.06 & $1.23-3.44$ & 2.34 & $1.13-4.82$ & 0.021 \\
\hline GAF-score (reference category $=41-50$ ) & 1 & - & 1 & - & 0.00 \\
\hline $31-40$ & 2.90 & $1.80-4.65$ & 3.07 & $0.94-10.09$ & 0.064 \\
\hline $21-30$ & 2.84 & $1.08-7.46$ & 3.23 & $1.08-9.69$ & 0.036 \\
\hline $10-20$ & 3.11 & $1.09-8.86$ & 2.52 & $1.44-4.41$ & 0.001 \\
\hline Number of diagnoses Axis I (reference category $=1$ ) & 1 & - & 1 & - & 0.088 \\
\hline 2 diagnoses & 1.78 & $1.11-2.88$ & 1.80 & $1.01-3.20$ & 0.047 \\
\hline$>2$ diagnoses & 2.22 & $1.24-3.98$ & 1.80 & $0.87-3.75$ & 0.113 \\
\hline \multicolumn{6}{|l|}{ Continuous $^{\mathrm{c}}$} \\
\hline Number of psychosocial problems Axis IV (0-9) & 1.34 & $1.20-1.51$ & 1.25 & $1.08-1.43$ & 0.002 \\
\hline Number of used psychiatric services during last year $(0-7)$ & 1.22 & $1.06-1.40$ & 0.79 & $0.61-1.04$ & 0.095 \\
\hline \multicolumn{6}{|l|}{ Model 2: perception-related variables $(p \leq 0.10)$} \\
\hline \multicolumn{6}{|l|}{ Continuous $^{\mathrm{c}}$} \\
\hline 'I feel powerless towards this patient' (1-7) & 1.75 & $1.51-2.20$ & 1.51 & $1.27-1.81$ & 0.000 \\
\hline 'I feel that this patient is able but unwilling to change' (1-7) & 1.35 & $1.17-1.56$ & 1.18 & $0.99-1.40$ & 0.072 \\
\hline 'I am pessimistic about the patient's change capacities' (1-7) & 1.37 & $1.21-1.56$ & 1.30 & $1.07-1.59$ & 0.009 \\
\hline 'This patient causes trouble within his/her family or social system' (1-7) & 1.29 & $1.16-1.44$ & 1.20 & $1.02-1.41$ & 0.027 \\
\hline 'This patient does not receive intensive treatment while he/she should' (1-7) & 1.57 & $1.31-1.80$ & 1.30 & $1.13-1.49$ & 0.000 \\
\hline \multicolumn{6}{|l|}{ Model 3: all remaining variables combined $(p \leq 0.05)$} \\
\hline \multicolumn{6}{|l|}{ Dichotomous } \\
\hline $\mathrm{CPN}$ contacts per week $(\leq 1 />1)$ & 2.65 & $1.75-4.02$ & 1.25 & $1.09-1.44$ & 0.001 \\
\hline Use of locked admission ward during last year (no/yes) & 2.06 & $1.23-3.44$ & 2.81 & $1.70-4.66$ & 0.000 \\
\hline \multicolumn{6}{|l|}{ Continuous $^{\mathrm{c}}$} \\
\hline Number of psychosocial problems Axis IV (1-9) & 1.34 & $1.20-1.51$ & 2.18 & $1.20-3.97$ & 0.011 \\
\hline 'I feel powerless towards this patient' (1-7) & 1.75 & $1.51-2.20$ & 1.67 & $1.42-1.98$ & 0.000 \\
\hline 'I feel that this patient is able but unwilling to change' (1-7) & 1.35 & $1.17-1.56$ & 1.27 & $1.06-1.51$ & 0.008 \\
\hline 'I am pessimistic about the patient's change capacities' (1-7) & 1.37 & $1.21-1.56$ & 1.19 & $1.01-1.39$ & 0.035 \\
\hline
\end{tabular}

${ }^{a}$ Bivariate OR, not corrected for other variables

b Adjusted OR, corrected for other variables in the model

${ }^{c}$ ORs of continuous variables increase with each unit increase on given scale or number

from ours, prevalence percentages cannot be readily compared.

In the final logistic model, six variables were independently related to the outcome of 'difficulty', none of which were related to the patient's diagnosis. Weakly significant correlations of certain diagnoses (e.g. substance abuse disorder, dissociative disorder, cluster-B personality disorder) were lost in the multivariable analyses. Of the six variables, three were related to professionals' perceptions of patients and their interactions with them (feeling powerless, feeling that the patient is able but unwilling to change, and pessimism about the patient's change potential). Two other variables were treatment-related (number of contacts per week and admission to a locked ward in the last year), showing that high service use correlates with perceived difficulty. The strongest relation, however, existed between the current number of psychosocial problems and perceived difficulty. In summary, the model shows the domination of professionals' subjective perceptions of patients, followed by social and treatment 
variables. These findings lend most support to our previously described explanation of 'difficult' as referring to a complex treatment situation in which the patient has many social problems and uses services intensively and the professional has several negative perceptions related to these patient problems. These outcomes fit in well with what is generally considered the designated role of CPNs in mental health care, namely to treat long-term patients with many complex psychiatric and psychosocial problems that have been unsuccessful in earlier treatment. They also show, however, that this is not an easy task.

In previous research, an important factor in the qualification of non-psychotic patients as difficult was the professional's perception of patients as 'able but unwilling to change or behave differently' [15]. In the present study, this perception-related variable was also retained in the multivariable model. Patients that are considered able to make changes in their lives may easily be considered in less need and less deserving of care than others. Irrespective of its correctness, this notion may add to a discrepancy of perceived need between patient and professional, which has been found to be persistent [33], associated with lower quality of life [34], and predictive of disagreement and negative therapeutic alliance [35]. There is some evidence that, for instance, patients with substance abuse [36] and personality disorders [37, 38] have higher needs than patients with psychotic disorders. Also, non-psychotic patients reported more needs than their treating staff did, whereas in psychotic patients this was exactly the opposite [38]. Recent studies confirm this picture of higher staff-rated needs in psychotic patients [39-41], others do not [42, 43]. Hence, patients may want more from professionals than these think is necessary. This incongruence may be the root for perceived difficulty by professionals, which will be exemplified in the next paragraph.

The oft-noted differences between professionals' views of 'difficult' patients with psychotic disorders (as 'hardto-reach') and non-psychotic disorders (as 'dependent' or 'claiming') may be explained by disagreement over needs for care. Professionals tend to see patients with psychotic disorders as more or 'really' sick, compared to patients without a psychotic disorder. Thus, the needs of patients are scored lower by professionals, while patients themselves score them higher. Our research, however, shows a high number of psychosocial problems (mean 3.3) among patients with non-psychotic disorders. As such, high needs may be present, yet the judgement of needs as 'justified' remains partly arbitrary and agreement over care needs is unlikely to be reached through 'objective' measures. Recent research consistently suggests that negotiation over needs for care results in better outcomes [35, 44-46]. Even when professionals perceive needs to be lower than patients, as in non-psychotic patients, it may be wiser to negotiate than to ignore patient-rated needs.

Strengths and limitations

There are some methodological limitations to this research. Selection bias may have occurred through differential nonresponse to the CPN-survey. Yet, responders did not differ from non-responders on demographic variables. Furthermore, the subject of the questionnaire was generally stated, and therefore is it highly unlikely that non-responders would have perceived non-psychotic chronic patients differently than responders. The sampling of patients, through selection of the first patient meeting the criteria in the CPN's agenda, was beyond our direct control but since CPNs were unaware of the content of the following questions, it is unlikely that they have deliberately chosen more or less 'difficult' patients. Furthermore, information bias is a risk since information about patients is provided by their CPNs and errors cannot be ruled out. Although we do not know if these are random or systematic errors, we have reason to believe that the large number of observations largely evens out these possible errors. Last, in bivariate screening some variables (e.g. 'evidence-based practice') unexpectedly failed to reach statistical significance. However, these variables were few in number, their $p$ value was well above the preset level of 0.20 , and the number of observations was sufficiently high, thus indicating a very low probability of non-detection of true associations.

The strength of this study lies in the large number of CPNs involved and the patients described. To our knowledge, similar research into the relevant clinical problem of 'difficult' non-psychotic patients has not been carried out on this scale. The electronic format of the questionnaire strongly reduced missing and inaccurate data to an absolute minimum (only $1.6 \%$ of the returned questionnaires were partly invalid). Through this design, we were able to reach CPNs evenly spread out over the Netherlands, thus representing different mental health institutions. The Delphivariables were valid translations of data provided by community mental health experts in an extensive Delphistudy that has been reported on in detail before [15]. We have reason to believe that the results of our study also apply to CPNs outside the Netherlands since their role is relatively comparable worldwide [28]. They often, if not always in long-term care, work in close collaboration with psychiatrists. Psychiatrists tend to largely depend on the information provided by $\mathrm{CPNs}$, which makes $\mathrm{CPNs}^{\prime}$ perception of the patient highly relevant to psychiatrists' own role and care in relation to the patient. The extent to which our results apply to other front-line professionals (e.g. other psychiatric nurses, social workers or occupational therapists) is uncertain and warrants more research, but as of yet 
we have no reason to assume that these key clinicians perceive patients very differently.

Practice implications

The implications for clinical practice partly depend on the predictive qualities of our models, to be assessed in longitudinal research. If it is possible to accurately predict perceived patient difficulty, the predictive variables may be used in a screening tool. Then, preventive actions may be taken to prevent possible future perception of these patients as difficult. Such preventive actions may consist of, for instance, increased attention for the therapeutic alliance between patient and professional, a focus on congruence of patient-rated and professional-rated needs for care, and organizational changes that facilitate high-quality care for patients in complex treatment situations. The overall purpose of these preventive measures, implemented through training and supervision, would be in line with our findings, be to redefine difficulty from an individual patient characteristic into a characteristic of the treatment situation.

Acknowledgments Funding for this study was provided by ZonMW 'Geestkracht' (Grant 100-002-031), Altrecht Mental Health Care and Gelderse Roos Mental Health Care. We thank the DACPN and the participating CPNs for their efforts.

Conflict of interest statement The authors declare that they have no conflict of interest.

Open Access This article is distributed under the terms of the Creative Commons Attribution Noncommercial License which permits any noncommercial use, distribution, and reproduction in any medium, provided the original author(s) and source are credited.

\section{References}

1. Groves JE (1978) Taking care of the hateful patient. N Engl J Med 298:883-887

2. Lin EH, Katon W, Korff Von et al (1991) Frustrating patients: physician and patient perspectives among distressed high users of medical services. J Gen Intern Med 6:241-246

3. Jackson JL, Kroenke K (1999) Difficult patient encounters in the ambulatory clinic: clinical predictors and outcomes. Arch Intern Med 159:1069-1075

4. Hahn SR, Kroenke K, Spitzer RL et al (1996) The difficult patient: prevalence, psychopathology, and functional impairment. J Gen Intern Med 11:1-8

5. Steinmetz D, Tabenkin H (2001) The 'difficult patient' as perceived by family physicians. Fam Pract 18:495-500

6. Hinshelwood RD (1999) The difficult patient. The role of 'scientific psychiatry' in understanding patients with chronic schizophrenia or severe personality disorder. $\mathrm{Br} \mathrm{J}$ Psychiatry 174:187-190

7. Koekkoek B, Van Meijel B, Hutschemaekers G (2006) "Difficult patients" in mental health care: a review. Psychiatr Serv 57:795802
8. Rössler W, Lauber C, Sartorius N et al (2006) Patients with severe mental illness: a most difficult-to-treat patient population. Acta Psychiatr Scand 113(s429):7-8

9. Corrigan PW (2006) Language and stigma. Psychiatr Serv 57:1218

10. Neill JR (1979) The difficult patient: identification and response. J Clin Psychiatry 40:209-212

11. Koekkoek B, Van Meijel B, Schene A et al (2008) Clinical problems in the long-term care of patients with chronic depression. J Adv Nurs 62:689-697

12. Dewan MJ, Pies RW (eds) (2001) The difficult-to-treat psychiatric patient. American Psychiatric Publishing, Washington, DC

13. Koekkoek B, van Meijel B, Schene A et al (2009) Clinical problems in community mental health care for patients with severe borderline personality disorder. Community Ment Health J 45:508-516

14. Koekkoek B, van Meijel B, Schene A et al (2009) A Delphi study of problems in providing community care to patients with nonpsychotic chronic mental illness. Psychiatr Serv 60:693-697

15. Koekkoek B, van Meijel B, Schene A et al (2009) Problems in psychiatric care of 'difficult patients': a Delphi-study. Epidemiol Psichiatr Soc 18:323-330

16. Horvath AO, Luborsky L (1993) The role of the therapeutic alliance in psychotherapy. J Consult Clin Psychol 61:561-573

17. Martin DJ, Garske JP, Davis MK (2000) Relation of the therapeutic alliance with outcome and other variables: a meta-analytic review. J Consult Clin Psychol 68:438-450

18. Kent S, Fogarty M, Yellowlees P (1995) Heavy utilization of inpatient and outpatient services in a public mental health service. Psychiatr Serv 46:1254-1257

19. Kent S, Fogarty M, Yellowlees P (1995) A review of studies of heavy users of psychiatric services. Psychiatr Serv 46:1247-1253

20. Roick C, Gartner A, Heider D et al (2002) Heavy users of psychiatric care. Psychiatr Prax 29:334-342 in German

21. Arvidsson H (2003) Met and unmet needs of severely mentally ill persons-the Psychiatric Care Reform in Sweden. Soc Psychiatry Psychiatr Epidemiol 38:373-379

22. Keown P, Holloway F, Kuipers E (2002) The prevalence of personality disorders, psychotic disorders and affective disorders amongst the patients seen by a community mental health team in London. Soc Psychiatry Psychiatr Epidemiol 37:225-229

23. Greenwood N, Chisholm B, Burns T et al (2000) Community mental health team case-loads and diagnostic case-mix. Psychiatr Bull 24:290-293

24. Hunter M, Jadresic D, Blaine A et al (2002) Two weeks in the life of a community mental health team: a survey of case-mix and clinical activity in the north-west of Sheffield. Psychiatr Bull 26:9-11

25. Ruggeri M, Salvi G, Bonetto C et al (2007) Outcome of patients dropping out from community-based mental health care: a 6-year multiwave follow-up study. Acta Psychiatr Scand 114(s437):42 52

26. Van Hoof F, Wolf J (1995) Profession: CPN. A survey into the work and future perspectives of community psychiatric nurses. NcGv, Utrecht in Dutch

27. World Health Organization (2007) Atlas: nurses in mental health. WHO, Geneva

28. Koekkoek B, Van Meijel B, Schene A et al. (2009) Community psychiatric nursing in the Netherlands: a survey of a thriving but threatened profession. J Psychiatr Ment Health Nurs 16:822-828

29. Ruggeri M, Leese M, Thornicroft G et al (2000) Definition and prevalence of severe and persistent mental illness. Br J Psychiatry 177:149-155

30. Modestin J, Greub E, Brenner HD (1986) Problem patients in a psychiatric inpatient setting. An explorative study. Eur Arch Psychiatry Neurol Sci 235:309-314 
31. Twisk JWR (2007) Introduction to applied biostatistics. Elsevier Gezondheidszorg, Maarssen in Dutch

32. Hosmer DW, Lemeshow S (1989) Applied logistic regression. Edward Arnold, London

33. Lasalvia A, Bonetto C, Salvi G et al (2007) Predictors of changes in needs for care in patients receiving community psychiatric treatment: a 4-year follow-up study. Acta Psychiatr Scand 114(s437):31-41

34. Wiersma D (2006) Needs of people with severe mental illness. Acta Psychiatr Scand 113(s429):115-119

35. Junghan UM, Leese M, Priebe S et al (2007) Staff and patient perspectives on unmet need and therapeutic alliance in community mental health services. Br J Psychiatry 191:543-547

36. Ruggeri M, Leese M, Slade M et al (2004) Demographic, clinical, social and service variables associated with higher needs for care in community psychiatric service patients. The South Verona Outcome Project 8. Soc Psychiatry Psychiatr Epidemiol 39:60-68

37. Hayward M, Slade M, Moran PA (2006) Personality disorders and unmet needs among psychiatric inpatients. Psychiatr Serv 57:538-543

38. Lasalvia A, Ruggeri M, Mazzi MA et al (2000) The perception of needs for care in staff and patients in community-based mental health services. The South-Verona Outcome Project 3. Acta Psychiatr Scand 102:366-375

39. Arvidsson H (2001) Needs assessed by patients and staff in a Swedish sample of severely mentally ill subjects. Nord J Psychiatry 55:311-317
40. Foldemo A, Ek AC, Bogren L (2004) Needs in outpatients with schizophrenia, assessed by the patients themselves and their parents and staff. Soc Psychiatry Psychiatr Epidemiol 39:381-385

41. Fleury MJ, Grenier G, Lesage A (2006) Agreement between staff and service users concerning the clientele's mental health needs: a Quebec study. Can J Psychiatry 51:281-286

42. Slade M, Phelan M, Thornicroft G (1998) A comparison of needs assessed by staff and by an epidemiologically representative sample of patients with psychosis. Psychol Med 28:543-550

43. Slade M, Phelan M, Thornicroft G et al (1996) The Camberwell Assessment of Need (CAN): comparison of assessments by staff and patients of the needs of the severely mentally ill. Soc Psychiatry Psychiatr Epidemiol 31:109-113

44. Lasalvia A, Bonetto C, Malchiodi F et al (2005) Listening to patients' needs to improve their subjective quality of life. Psychol Med 35:1655-1665

45. Lasalvia A, Bonetto C, Tansella M et al (2008) Does staff-patient agreement on needs for care predict a better mental health outcome? A 4-year follow-up in a community service. Psychol Med 38:123-133

46. Joosten EA, de Jong CA, de Weert-van Oene GH et al (2009) Shared decision-making reduces drug use and psychiatric severity in substance-dependent patients. Psychother Psychosom 78:245253 